\title{
A Comparative Study of Age Related Hearing Loss among Diabetic Patients
}

\author{
Dr. G. K. Pathak ${ }^{1}$, Dr.Sritama De ${ }^{2}$ \\ ${ }^{1}$ Professor And Head, ${ }^{2}$ Resident, Dept. Of Otorhinolaryngology And Head And Neck Surgery, Gauhati Medical \\ College, Guwahati(Assam)
}

\begin{abstract}
:
Aim:Our study aims at evaluate auditory dysfunction in patients with diabetes mellitus aged above 50 years as compared to non-diabetic patient,it's relationshipwith the duration of diabetes and HbAlc levels and to evaluatethe central auditory pathway involvement in diabetic patients by Brainstem Evoked response audiometry(BERA).

Materials And Methods: A cross sectional, comparative clinical study on 50 Diabetic and 50 Non-Diabetic patients, aged above 50 years with age and sex matched (controls) was carried out from $1^{\text {st }} \mathrm{July}, 2015$ to $30^{\text {th }}$ June, 2016. All patients were evaluated for hearing loss by subjecting to pure tone audiometry and BERA and blood investigations like Fasting Blood sugar, Post Prandial Sugar, HbAlc were done and recorded.

Results: Sensorineural deafness was seen in 68\% of the diabetics with hearing loss more towards the higher frequencies. A significant relationship between duration of the diabetes, HbAlc and hearing loss was observed. In BERA significant delay was found in the absolute latency of wave III and wave V and in the interpeak latency of wave I-III, III-V and I-V.

Conclusion: Prevalence of hearing loss was found to be high in type 2 diabetic patients (68\%). Increase in the prevelence of sensorineural hearing loss (SNHL) was seen with an increase in duration of diabetes. BERA revealed that the eight nerve transmission till the level of cochlear nucleus is not altered however there is in transmission of the auditory stimulus in the auditory pathway of diabetics at the level of brainstem and midbrain.
\end{abstract}

Keywords: Pure tone audiometry, SNHL, BERA, HbAlc, diabetes

\section{Introduction}

Diabetes mellitus comprises a group of common metabolic disorders that share the phenotype of hyperglycemia. The two broad categories of DM are designated as type-1 and type- 2 . The metabolic dysregulation associated with DM causes secondary patho-physiological changes in multiple organ systems. ${ }^{[1]}$ India has a diabetic population around 50 million people which is expected to be doubled by $2030^{[2]}$. It is considered almost 278 million people around the world have hearing loss ranging from moderate to profound hearing loss and more than half of them is preventable by early diagnosis and treatment, of which diabetes mellitus takes a major part. Various studies has shown that diabetes mellitus causes sensorineural hearing loss (SNHL), but the relationship between the two has been highly controversial.The study of auditory brain stem evoked responses provides an opportunity to evaluate the functional integrity of auditory pathway from inner ear to upper brain stem. Jewett et al, (1970) gave the topographical location of generation centres of waves I-V. However only wave I, III \& V are recorded reliably enough to be routinely used in clinical applications (American Electroencephalographic Society 1984) and they primarily represent the volume conducted electrical activity from the cochlear nerve, pons and midbrain respectively. ${ }^{[3]}$ The present work aims at evaluating auditory dysfunction in patients with diabetes mellitus aged above 50 years as compared to non-diabetic patient and the relation between duration of diabetes and HbA1c levels with the prevalence of hearing loss. The study will also focus on finding out central auditory pathway involvement in diabetes mellitus by BERA.

\section{Aims And Objectives}

i). To evaluate occurrence of auditory dysfunction in patients with type 2 diabetes patients aged above 50 years and compare the same with age matched control groups

ii). To study the relation between the prevalence of hearing loss, the duration and severity of type 2 diabetes mellitus

iii). To evaluate hearing loss in controlled and uncontrolled diabetes mellitus.

iv). To find out central auditory pathway involvement in diabetes mellitus by BERA. 


\section{Materials And Methods}

After approval by the Institutional ethical committee, this study was conducted under the Department Of Otorhinolaryngology and Head and Neck Surgery, Gauhati Medical College and Hospital.The present study is a hospital based cross sectional, comparative clinical study conducted from $1^{\text {st }} \mathrm{July}, 2015$ to $30^{\text {th }} \mathrm{June}, 2016$. The details of 50 Diabetic and 50 Non-Diabetic patients, aged above 50 years who attended the Department of Otorhinolaryngology and Head and Neck Surgery, Gauhati Medical College and Hospital were taken.

\section{Inclusion Criteria -}

I. Diabetic patients aged $>50$ years with/without hearing loss and

II. Non-diabetic controls who were age and sex matched without any comorbidities.

\section{Exclusion Criteria -}

I. Patients $<50$ years,

II. Patients with middle ear pathology,

III. Patients with known cause of sensorineural hearing loss (congenital hearing loss, Menière's disease, Labyrinthitis, temporal bone fracture, syphillis, meningitis),

IV. Patients with history of ototoxic drug intake, hypertension, cardiac diseases and renal failure.

V. Patient taking any medication which might be expected to interfere with the functioning of central nervous system. (Methyldopa, reserpine, phenytoin, Antipsychotic, antidepressants)

All patients underwent pure tone audiometry by Hughson-Westlake method.The minimum threshold was identified at all frequencies 250,500,1000, 2000, 4000 and $8000 \mathrm{~Hz}$, in air conduction whereas only till $4000 \mathrm{~Hz}$ in bone conduction. The patients were grouped into different age groups 51-60 years, 61-70 years 7180 years and 81-90 years in both cases and controls. The average pure tone threshold was taken at low $(250 \mathrm{~Hz}$, $500 \mathrm{~Hz}$ and $1000 \mathrm{~Hz}$ ) and high frequencies $(2000 \mathrm{~Hz}, 4000 \mathrm{~Hz}$ and $8000 \mathrm{~Hz}$ ) and then the minimum difference was calculated between diabetic and non-diabetic patients.

Fasting and post prandial blood sugar and HbA1c results were estimated by Vitros auto-analyser, Central Clinical laboratory, Gauhati medical College. The cases and control groups were further divided into HbA1c level $<7 \%$ good glycaemic control, $7 \%-8 \%$ fair glycaemic control and $>8 \%$ poor glycaemic control. BERA was done in both the groups to find out the central auditory pathway involvement in diabetic patients. Parameters for the study were absolute latencies of wave I, III and V, interpeak latencies I-III, III-V and I-V and intra peak latency of wave $\mathrm{V}$.

Results were analysed and the quantitative variables used to compare the case and control groups were treated using Student's t-test for independent variables. Statistical significance was attributed when $p<0.05$. Results were considered highly significant if $\mathrm{p}$ value was $<0.001$.

The hearing threshold was graded as per World Health Organization (WHO) guidelines ${ }^{[4]}$, $\mathbf{0}-\mathbf{2 5} \mathbf{d B}$ - hearing within normal limits

26 - 40 dB - mild hearing loss

41 - $55 \mathrm{~dB}$ - moderate hearing loss

56 - 70 dB - moderately severe hearing loss

71 - $90 \mathrm{~dB}$ - severe hearing loss

$>90 \mathrm{~dB}$ - profound hearing loss

\section{Prevelance Of Snhl}

\section{Results And Observations}

In this study of 50 type 2 diabetic patients, 34 had sensorineural hearing loss (SNHL) - 68\% ( $\mathrm{n}=50)$ and the rest 16 patients had hearing within normal limits $-32 \%(n=50)$. Of the 34 patients with sensorineural hearing loss only 17 patients complained of hearing loss.

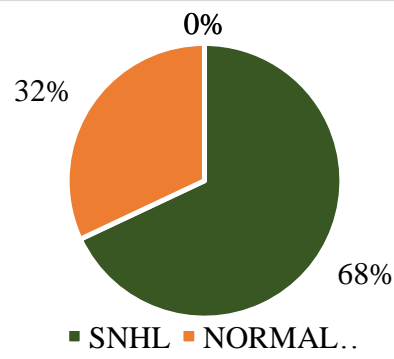

Pie Diagram Showing Sensorineural Hearing Loss Among Cases 
Table 1: Age Distribution Of Cases And Controls And Snhl

The patients involved in the study was divided into four groups based on age: $51-60$ years, $61-70$ years, $71-$ 80 years, and $81-90$ years of age.

Mean age of cases- 61.82 years

Mean age of controls- 60.86 years

\begin{tabular}{|l|l|l|l|l|l|l|}
\hline $\begin{array}{l}\text { Age group } \\
\text { (years) }\end{array}$ & $\begin{array}{l}\text { Total no } \\
\text { of cases } \\
\text { (Diabetic) }\end{array}$ & $\begin{array}{l}\text { Total no } \\
\text { of cases } \\
\text { with } \\
\text { SNHL }\end{array}$ & $\begin{array}{l}\text { Total no of } \\
\text { controls } \\
\text { Non } \\
\text { Diabetic) }\end{array}$ & $\begin{array}{l}\text { Total no of Percentage } \\
\text { controls with } \\
\text { SNHL }\end{array}$ & (n) \\
\hline $51-60$ & 28 & 17 & $60.71(\mathrm{n}=28)$ & 27 & 9 & $33.33(\mathrm{n}=27)$ \\
\hline $61-70$ & 14 & 10 & $71.43(\mathrm{n}=14)$ & 17 & 7 & $41.17(\mathrm{n}=17)$ \\
\hline $71-80$ & 6 & 5 & $83.33(\mathrm{n}=6)$ & 4 & 3 & $75(\mathrm{n}=4)$ \\
\hline $81-90$ & 2 & 2 & $100(\mathrm{n}=2)$ & 2 & 2 & $100(\mathrm{n}=2)$ \\
\hline
\end{tabular}

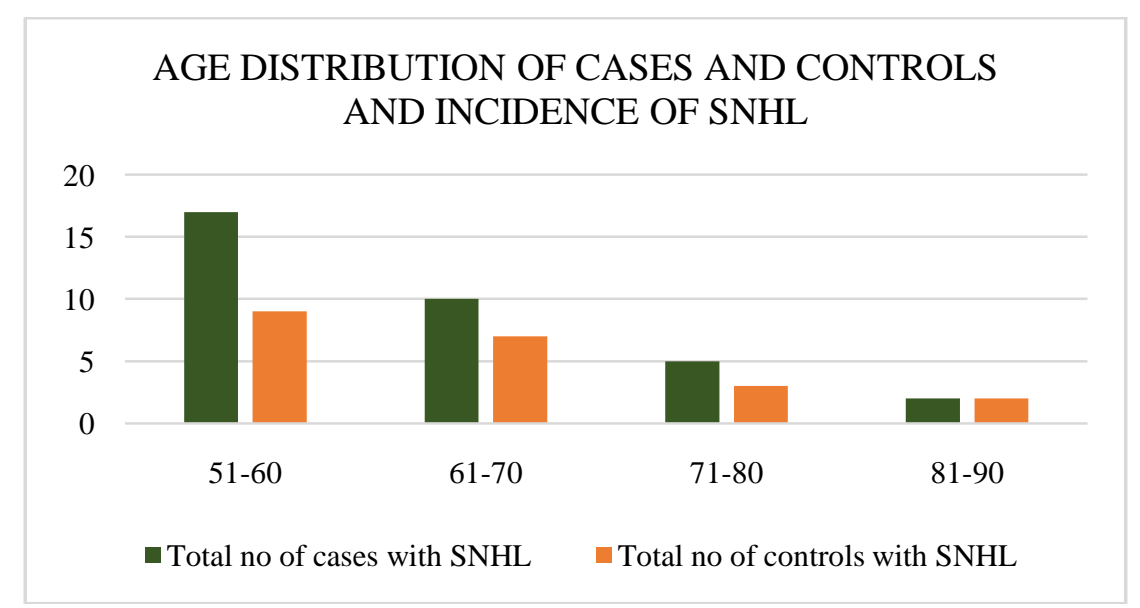

\section{Histogram Showing Age Distribution Of Cases And Controls And Incidence Of Snhl}

As we can see from the table above, the number of people with hearing loss among the cases in 51-60y $(60.71 \%, \mathrm{n}=28), 61-70 \mathrm{y}(71.43 \%, \mathrm{n}=14)$ and $71-80 \mathrm{y}(83.33 \%, \mathrm{n}=6)$ is greater than those in the controls groups in 51-60y $(33.33 \%, \mathrm{n}=27), 61-70 \mathrm{y}(41.17 \%, \mathrm{n}=17)$ and $71-80 \mathrm{y}(75 \%, \mathrm{n}=4)$. However no difference is seen in the age group of $81-90 y$ were all the cases presented with hearing loss among both cases and controls. Age related degenerative process leading to hearing loss might have been a confounding factor for this finding.

Table 2: Sex Distribution Of Cases And Controls And Snhl

The male female ratio of cases in this study was 2.5:1. Among the 36 males, 24 patients was found to have sensorineural hearing loss $-66.67 \%(\mathrm{n}=36)$ and among the 14 females, 10 patients had sensorineural hearing loss $-71.42 \%(\mathrm{n}=14)$.

\begin{tabular}{|l|l|l|l|}
\hline Sex & $\begin{array}{l}\text { Diabetic } \\
\text { (Cases) }\end{array}$ & $\begin{array}{l}\text { Total no of cases with } \\
\text { SNHL }\end{array}$ & Percentage \\
\hline Males & 36 & 24 & $66.67(\mathrm{n}=36)$ \\
\hline Females & 14 & 10 & $71.42(\mathrm{n}=14)$ \\
\hline
\end{tabular}

Total no of cases with SNHL

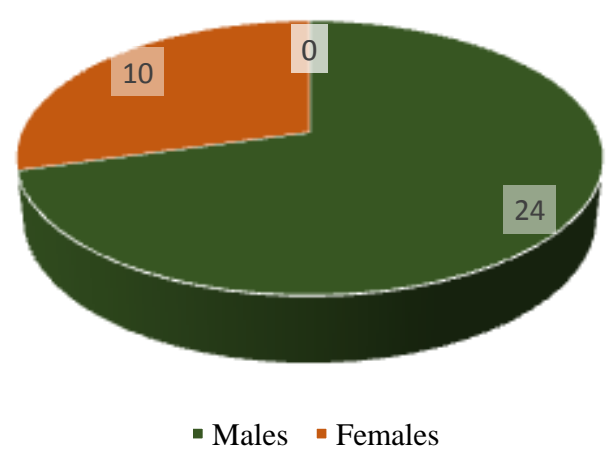


Table 3: Duration Of Diabetes And Snhl

\begin{tabular}{|l|l|l|l|}
\hline Duration(in years) & Total & Number of cases with SNHL & Percentage \\
\hline $0-5$ & 19 & 9 & $47.37(\mathrm{n}=19)$ \\
\hline $6-10$ & 19 & 13 & $68.42(\mathrm{n}=19)$ \\
\hline $11-15$ & 3 & 3 & $100(\mathrm{n}=3)$ \\
\hline $16-20$ & 7 & 7 & $100(\mathrm{n}=7)$ \\
\hline $21-25$ & 2 & 2 & $100(\mathrm{n}=2)$ \\
\hline
\end{tabular}

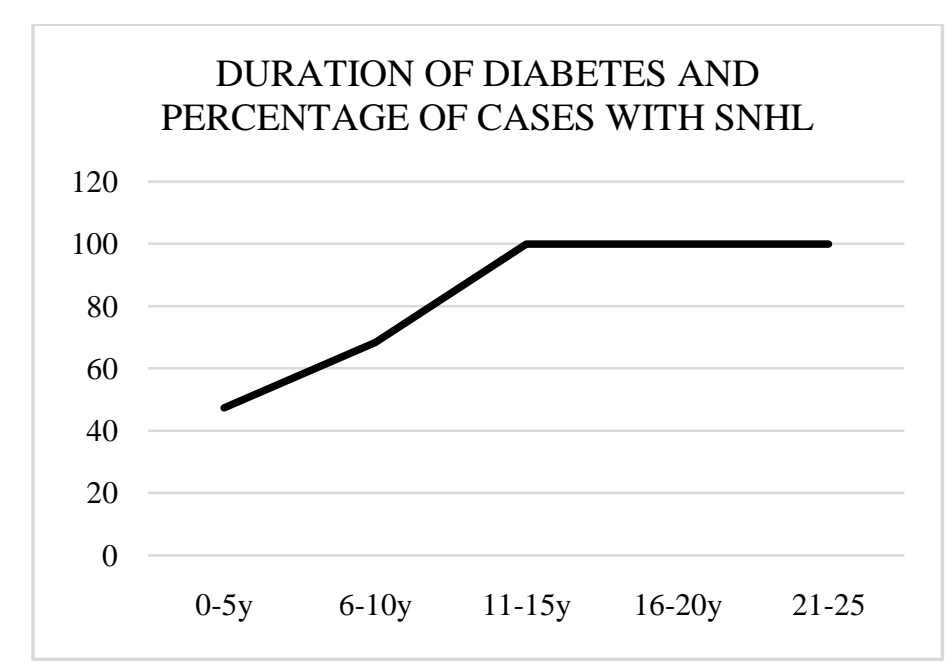

Line Diagram Showing Duration Of Diabetes And SnhlIn our study we found that the number of cases of SNHL increased with the increase in duration of diabetes. However, after 10y of duration no difference was found. Cases with more than 10 years of duration of diabetes were more than 70years of age hence age related hearing loss could have been a confounding factor.

Table 4: Hba1c And Snhl

\begin{tabular}{|l|l|l|l|}
\hline HbA1c & Total number of cases & Number of cases with SNHL & Percentage $(\mathrm{n}=34)$ \\
\hline Less than $7 \%$ & 16 & 9 & 26.47 \\
\hline $7 \%-8 \%$ & 10 & 5 & 14.71 \\
\hline More than $8 \%$ & 24 & 20 & 58.82 \\
\hline TOTAL & 50 & 34 & 100 \\
\hline
\end{tabular}

Out of the 34 patients of SNHL, 26.47\%, 14.71\%, 58.82\% cases had HbA1c levels less than 7\%, 7\%$8 \%$ and more than $8 \%$ respectively. Hence our study shows that patients with uncontrolled sugar levels $(68 \%$, $\mathrm{n}=50)$ had more incidence of sensorineural hearing loss $(73.53 \%, \mathrm{n}=34)$ than patients with controlled sugar levels $(26.47 \%, \mathrm{n}=34)$.

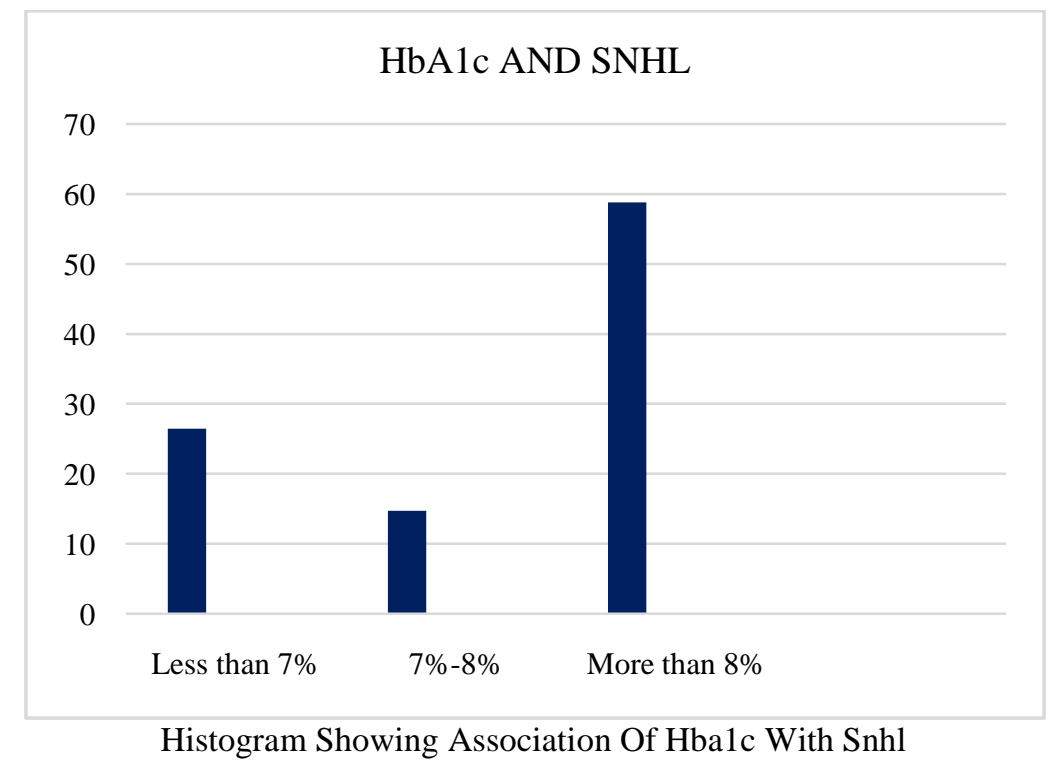


Table 5: Comparison Between Control And Case Group Hearing Thresholds For Right (Re) And Left Ears (Le) From $250 \mathrm{~Hz}$ To $8000 \mathrm{~Hz}$

This table presents the statistics on auditory thresholds based on the frequencies, groups, and ears studied. Unpaired student's t-test was performed and the p-values obtained are presented.

\begin{tabular}{|c|c|c|c|c|c|c|c|c|c|}
\hline Frequency & Side & & $\mathrm{n}$ & Mean & Median & Min. & Max. & S.D. & p value \\
\hline \multirow[t]{4}{*}{$250 \mathrm{~Hz}$} & \multirow[t]{2}{*}{$\mathrm{RE}$} & Cases & 50 & 30.7 & 27.5 & 10 & 70 & 15.59 & \multirow[t]{2}{*}{0.04} \\
\hline & & Controls & 50 & 25.6 & 20 & 10 & 65 & 14.72 & \\
\hline & \multirow[t]{2}{*}{$\mathrm{LE}$} & Cases & 50 & 34.1 & 30 & 15 & 75 & 15.96 & \multirow[t]{2}{*}{0.004} \\
\hline & & Controls & 50 & 25.9 & 20 & 10 & 65 & 14.34 & \\
\hline \multirow[t]{4}{*}{$500 \mathrm{~Hz}$} & \multirow[t]{2}{*}{$\mathrm{RE}$} & Cases & 50 & 33.6 & 30 & 15 & 75 & 15.46 & \multirow[t]{2}{*}{0.008} \\
\hline & & Controls & 50 & 26.2 & 20 & 10 & 65 & 14.61 & \\
\hline & \multirow[t]{2}{*}{ LE } & Cases & 50 & 36.4 & 32.5 & 15 & 75 & 16.61 & \multirow[t]{2}{*}{0.0018} \\
\hline & & Controls & 50 & 27 & 20 & 10 & 65 & 14.53 & \\
\hline \multirow[t]{4}{*}{$1000 \mathrm{~Hz}$} & \multirow[t]{2}{*}{$\mathrm{RE}$} & Cases & 50 & 34.5 & 30 & 15 & 80 & 15.85 & \multirow[t]{2}{*}{0.016} \\
\hline & & Controls & 50 & 27.6 & 20 & 10 & 70 & 15.63 & \\
\hline & \multirow[t]{2}{*}{$\mathrm{LE}$} & Cases & 50 & 36.7 & 30 & 15 & 85 & 17.48 & \multirow[t]{2}{*}{0.006} \\
\hline & & Controls & 50 & 28.2 & 22.5 & 10 & 70 & 15.32 & \\
\hline \multirow[t]{4}{*}{$2000 \mathrm{~Hz}$} & \multirow[t]{2}{*}{$\mathrm{RE}$} & Cases & 50 & 36.5 & 35 & 10 & 85 & 17.61 & \multirow[t]{2}{*}{0.014} \\
\hline & & Controls & 50 & 28.9 & 25 & 10 & 75 & 15.95 & \\
\hline & \multirow[t]{2}{*}{$\mathrm{LE}$} & Cases & 50 & 38.9 & 35 & 15 & 90 & 18.77 & \multirow[t]{2}{*}{0.0027} \\
\hline & & Controls & 50 & 28.9 & 25 & 10 & 75 & 15.98 & \\
\hline \multirow[t]{4}{*}{$4000 \mathrm{~Hz}$} & \multirow[t]{2}{*}{$\mathrm{RE}$} & Cases & 50 & 48.4 & 45 & 15 & 85 & 16.63 & \multirow[t]{2}{*}{$<0.001^{*}$} \\
\hline & & Controls & 50 & 31.4 & 25 & 10 & 80 & 16.31 & \\
\hline & \multirow[t]{2}{*}{$\mathrm{LE}$} & Cases & 50 & 51.9 & 50 & 15 & 90 & 17.6 & \multirow[t]{2}{*}{$<0.001^{*}$} \\
\hline & & Controls & 50 & 32 & 27.5 & 10 & 80 & 16.19 & \\
\hline \multirow[t]{4}{*}{$8000 \mathrm{~Hz}$} & \multirow[t]{2}{*}{$\mathrm{RE}$} & Cases & 50 & 53 & 55 & 15 & 90 & 17.12 & \multirow[t]{2}{*}{$<0.001^{*}$} \\
\hline & & Controls & 50 & 34.7 & 30 & 15 & 80 & 16.47 & \\
\hline & \multirow[t]{2}{*}{$\mathrm{LE}$} & Cases & 50 & 56.2 & 60 & 15 & 90 & 17.68 & \multirow[t]{2}{*}{$<0.001^{*}$} \\
\hline & & Controls & 50 & 34.7 & 30 & 10 & 80 & 16.69 & \\
\hline
\end{tabular}

$\mathrm{p}$ value $<0.05$ is significant $\mathrm{p}$ value $<0.001$ is highly significant $(*)$ S.D. Standard Deviation

Statistically significant difference was found with audiometric thresholds in case group subjects when compared to controls at $250,500,1000$ and $2000 \mathrm{~Hz}$ for both ears. The results were found to be highly significant at higher frequencies: 4000 and $8000 \mathrm{~Hz}$.

Table 6: Comparison Of Absolute Latencies Of Brainstem Evoked Response Audiometry (Bera) Between Cases And Controls

BERA for all the cases and controls were performed at 110dB SPL (65dB nhl). This table presents the statistics on absolute latencies of BERA between cases and controls. Unpaired student's t-test was performed and the pvalues obtained are presented.

\begin{tabular}{|c|c|c|c|c|c|c|c|}
\hline & Side & & $\mathrm{n}$ & Mean & Median & S.D. & $\mathrm{p}$ value \\
\hline \multirow[t]{4}{*}{ Wave I } & \multirow[t]{2}{*}{$\mathrm{RE}$} & Cases & 50 & 1.72 & 1.7 & 0.17 & \multirow[t]{2}{*}{$0.27 *$} \\
\hline & & Controls & 50 & 1.7 & 1.68 & 0.12 & \\
\hline & \multirow[t]{2}{*}{$\mathrm{LE}$} & Cases & 50 & 1.74 & 1.7 & 0.17 & \multirow[t]{2}{*}{$0.45^{*}$} \\
\hline & & Controls & 50 & 1.74 & 1.72 & 0.07 & \\
\hline \multirow[t]{4}{*}{ Wave III } & \multirow[t]{2}{*}{$\mathrm{RE}$} & Cases & 50 & 3.87 & 3.78 & 0.27 & \multirow[t]{2}{*}{$<0.001$} \\
\hline & & Controls & 50 & 3.54 & 3.55 & 0.14 & \\
\hline & \multirow[t]{2}{*}{$\mathrm{LE}$} & Cases & 50 & 3.93 & 3.96 & 0.27 & \multirow[t]{2}{*}{$<0.001$} \\
\hline & & Controls & 50 & 3.6 & 3.62 & 0.16 & \\
\hline \multirow[t]{4}{*}{ Wave V } & \multirow[t]{2}{*}{$\mathrm{RE}$} & Cases & 50 & 5.97 & 5.91 & 0.24 & \multirow[t]{2}{*}{$<0.001$} \\
\hline & & Controls & 50 & 5.74 & 5.77 & 0.13 & \\
\hline & \multirow[t]{2}{*}{$\overline{\mathrm{LE}}$} & Cases & 50 & 6.03 & 6 & 0.24 & \multirow[t]{2}{*}{$<0.001$} \\
\hline & & Controls & 50 & 5.76 & 5.75 & 0.13 & \\
\hline
\end{tabular}

$\mathrm{p}$ value $<0.05$ is significant $\mathrm{p}$ value $<0.001$ is highly significantS.D. Standard Deviation *: not significantHighly significant difference was found in latencies of wave III and wave V between the control and study groups at $110 \mathrm{~dB}$ SPL (65dB nhl). 


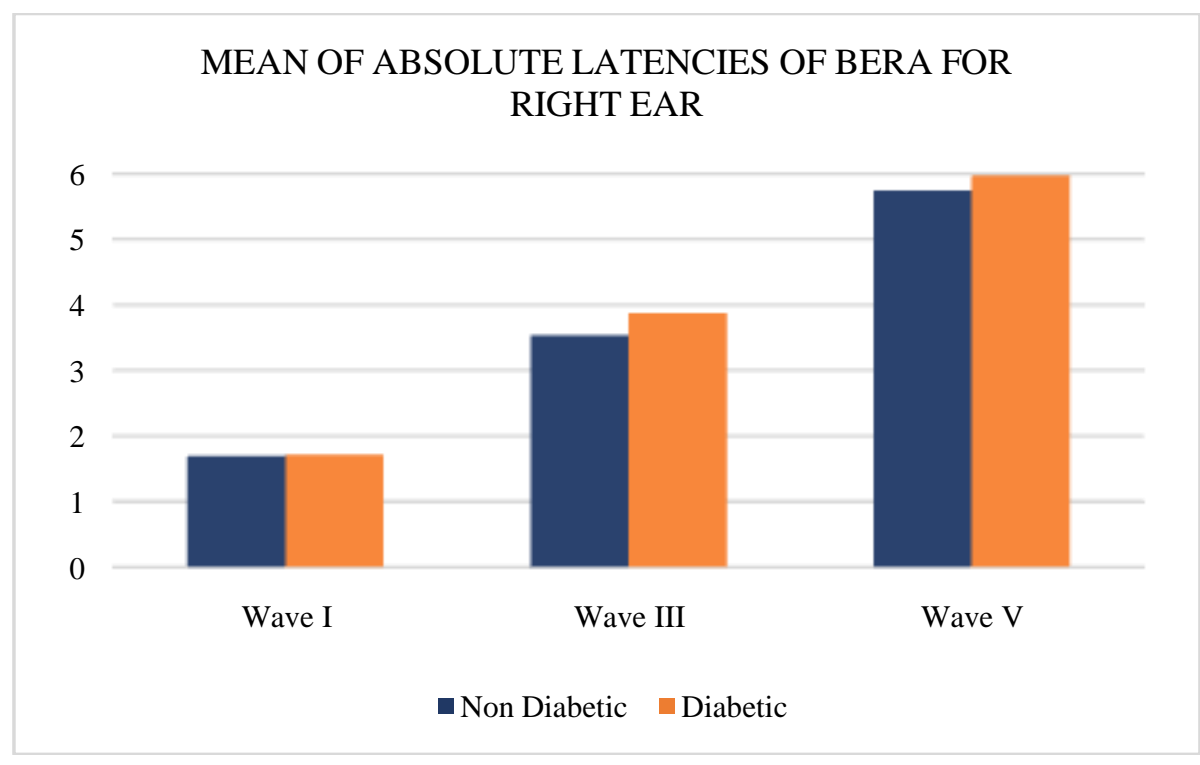

\section{Histogram Showing Comparison Of Mean Of Absolute Latencies Of Bera For Right Ear}

As we can see from the graph above the latency of wave I of right ear at 110dB SPL (65dB nhl) was found to be equal in the diabetics and controls. The latency of wave III of right ear was delayed by $0.33 \mathrm{~ms}$ at $110 \mathrm{~dB}$ SPL (65dB nhl) msec in diabetic group as compared to control group. The delay was found to be highly significant on statistical analysis. The latency of wave $\mathrm{V}$ of right ear was delayed by $0.23 \mathrm{~ms}$ at $110 \mathrm{~dB}$ SPL $(65 \mathrm{~dB} \mathrm{nhl})$ in diabetic group as compared to control group. The delay was found to be highly significant on statistical analysis.

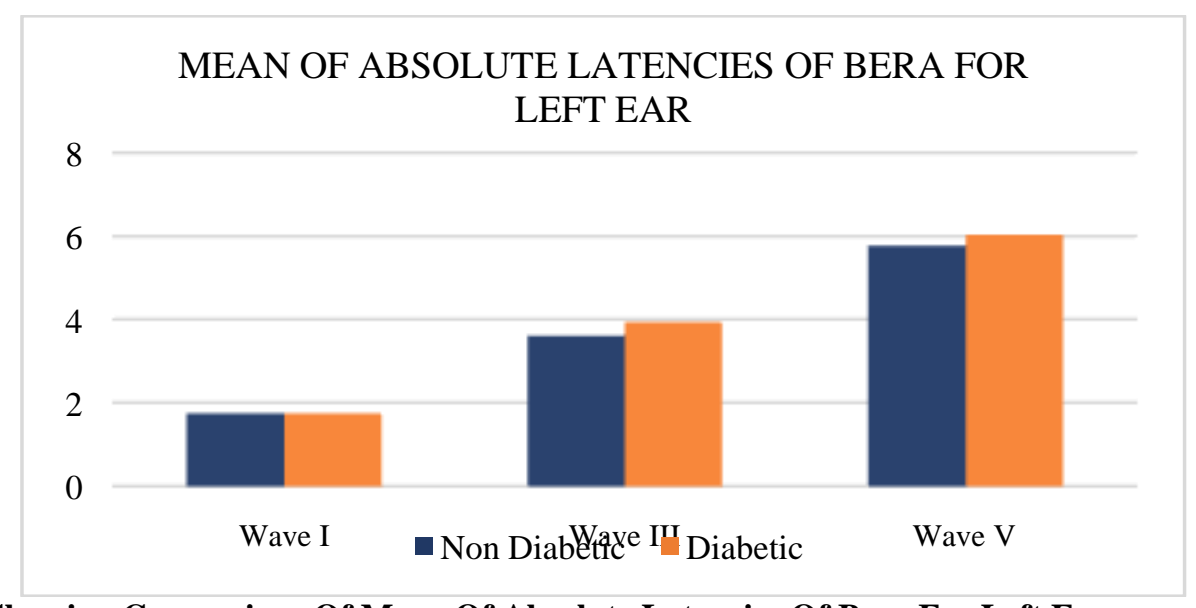

\section{Histogram Showing Comparison Of Mean Of Absolute Latencies Of Bera For Left Ear}

As we can see from the graph above the latency of wave I of left ear at 110dB SPL (65dB nhl) was found to be equal in the diabetics and controls. The latency of wave III of left ear was delayed by $0.33 \mathrm{~ms}$ at $110 \mathrm{~dB}$ SPL $(65 \mathrm{~dB} \mathrm{nhl})$ in diabetic group as compared to control group. The delay was found to be highly significant on statistical analysis. The latency of wave $\mathrm{V}$ of right ear was delayed by $0.27 \mathrm{~ms}$ at $110 \mathrm{~dB}$ SPL $(65 \mathrm{~dB} \mathrm{nhl})$ in diabetic group as compared to control group. The delay was found to be highly significant on statistical analysis.

Table 7: Comparison Of Interpeak Latencies Of Bera Between Cases And Controls

BERA for all the cases and controls were performed at 110dB SPL (65dB nhl). This table presents the statistics on interpeak latencies of BERA between cases and controls. Unpaired student's t-test was performed and the pvalues obtained are presented.

\begin{tabular}{|l|l|l|l|l|l|l|l|}
\hline & Side & & $\mathrm{n}$ & Mean & Median & S.D. & p value \\
\hline \multirow{3}{*}{ Wave I-III } & \multirow{2}{*}{ RE } & Cases & 50 & 2.39 & 2.39 & 0.29 & $<0.001$ \\
\cline { 3 - 8 } & & Controls & 50 & 2.14 & 2.13 & 0.12 & \\
\cline { 2 - 7 } & \multirow{2}{*}{ LE } & Cases & 50 & 2.46 & 2.46 & 0.22 & \multirow{2}{*}{$<0.001$} \\
\cline { 3 - 7 } & & Controls & 50 & 2.13 & 2.1 & 0.17 & \\
\hline
\end{tabular}


A Comparative Study Of Age Related Hearing Loss Among Diabetic Patients

\begin{tabular}{|l|l|l|l|l|l|l|l|}
\hline Wave III-V & \multirow{2}{*}{ RE } & Cases & 50 & 2.10 & 2.11 & 0.19 & $<0.001$ \\
\cline { 3 - 7 } & & Controls & 50 & 1.97 & 1.95 & 0.09 & \\
\cline { 2 - 7 } & \multirow{2}{*}{ LE } & Cases & 50 & 2.14 & 2.11 & 0.29 & \multirow{2}{*}{$<0.001$} \\
\cline { 3 - 7 } & & Controls & 50 & 1.98 & 1.95 & 0.12 & \\
\hline \multirow{3}{*}{ Wave I-V } & \multirow{2}{*}{ RE } & Cases & 50 & 4.4 & 4.39 & 0.31 & \multirow{2}{*}{$<0.001$} \\
\cline { 3 - 7 } & & Controls & 50 & 4.05 & 4.02 & 0.15 & \\
\cline { 2 - 7 } & \multirow{2}{*}{ LE } & Cases & 50 & 4.41 & 4.47 & 0.33 & \multirow{2}{*}{$<0.001$} \\
\cline { 3 - 7 } & & Controls & 50 & 4.07 & 4.06 & 0.17 & \\
\hline
\end{tabular}

$\mathrm{p}$ value $<0.05$ is significant $\mathrm{p}$ value $<0.001$ is highly significant S.D. Standard DeviationHighly significant difference was found in the interpeak latencies of wave I-III, III-V and I-V between the control and study groups at $110 \mathrm{~dB}$ SPL $(65 \mathrm{~dB} \mathrm{nhl})$.

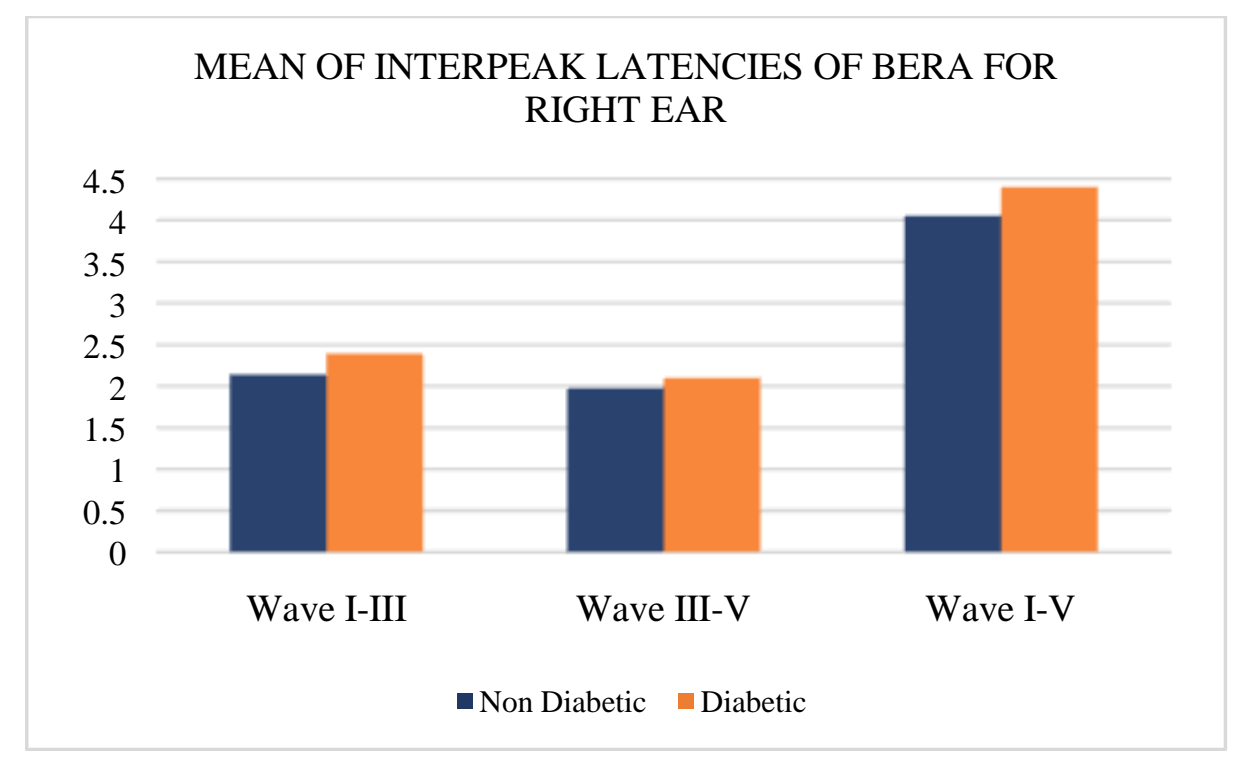

\section{Histogram Showing Comparison Of Mean Of Interpeak Latencies Of Bera For Right Ear}

As we can see from the graph above that the interpeak latency of wave I-III, III-V, I-V of right ear was delayed by $0.25 \mathrm{~ms}, 0.13 \mathrm{~ms}$ and $0.35 \mathrm{~ms}$ respectively at $110 \mathrm{~dB}$ SPL $(65 \mathrm{~dB} \mathrm{nhl})$ in diabetic group as compared to control group. The delay was found to be highly significant on statistical analysis.

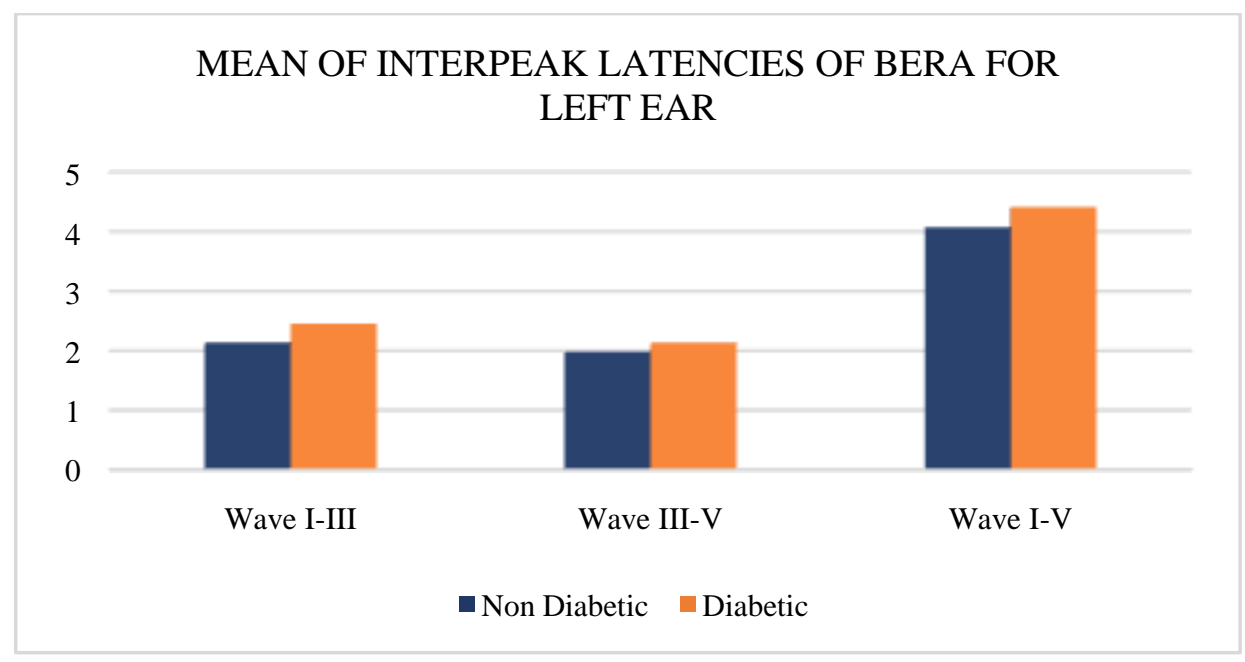

Histogram Showing Comparison Of Mean Of Interpeak Latencies Of Bera For Left Ear

As we can see from the graph above that the interpeak latency of wave I-III, III-V, I-V of left ear was delayed by $0.33 \mathrm{~ms}, 0.16 \mathrm{~ms}$ and $0.34 \mathrm{~ms}$ respectively at $110 \mathrm{~dB}$ SPL (65dB nhl) in diabetic group as compared to control group. The delay was found to be highly significant on statistical analysis. 


\section{Discussion}

Diabetes mellitus is a common metabolic disease affecting almost all age groups. There is a higher prevalence of hearing impairment in diabetic patients compared with non-diabetic patients. ${ }^{[5]}$ However, there is not enough evidence to solidly define diabetes mellitus as a cause of hearing loss. ${ }^{[6]}$

The two important factors seen in diabetics which affect hearing are: Diabetic angiopathy and neuropathy.Diabetes mellitus causes increased rate of triglyceride production due to insulin resistance. There is endothelial proliferation and accumulation of glycoproteins, with thickening of the capillary vessels in basement membranes. ${ }^{[7]}$ This results in impaired nutrient transportation through these thickened vessels resulting in decreased blood flow through narrowed vessels leading to secondary degeneration of vestibulocochlear nerve.Activation of polyol pathway, causes accumulation of sorbital within the neurons thereby reducing the myoinositol content and $\mathrm{Na}+/ \mathrm{K}+$ ATPase activity intracellularily leading to osmotic damage and swelling. ${ }^{[1]}$ Protein kinase $\mathrm{C}$ is implicated in increased production of cytokines, regulation of vascular permeability, flow, and increased synthesis of basement membranes which is seen to increase in diabetes. ${ }^{[1]}$ In addition to increased formation of advanced glycation products in collagen, DNA also contributes to tissue damage leading to cellular hypertrophy and hyperplasia. ${ }^{[1]}$ In the current study 50 diabetic (cases) and 50 non diabetic (controls) were studied and compared on different parameters.

Our study showed a prevalence of sensorineural hearing loss in $68 \%$ cases of type 2 diabetes mellitus. Similar results were found in the study by Friedman et. al. ${ }^{[8]}$ in 1975 (55\%);Rajendranet. al., ${ }^{[9]}$ in 2011(73.3\%)and Krishnappa et. al., ${ }^{[10]}$ in their study in 2014 (73.58\%). The cross sectional study done by Shafeeqet. al., ${ }^{[1]}$ in 2015 on 83 patients of type 2 DM patients reported the prevalence as $62.65 \%$. The mean age of cases and controls in our study was 61.82 years and 60.86 years respectively.

On comparing the sensorineural hearing loss in different age groups between cases and controls, [Table 1] the prevalence was found to be more among the diabetics as compared to non-diabetics in the age group of 51-60 years $(60.71 \%), 61-70$ years $(71.43 \%)$ and $71-80$ years $(83.33 \%)$. These findings were comparable with the cross sectional study done on 106 diabetics and 90 non-diabetics by Krishnappaet. al.(2014). ${ }^{[10]}$ Furthermore, no difference in the prevalence of SNHL was found between cases and controls in the age group of 81-90 years (both were 100\%) in our study. Age related degenerative process leading to hearing loss might have been a confounding factor for this finding. However in the study done by Krishnappaet. al.(2014) ${ }^{[10]}$ an incidence of $66.6 \%$ was found among the diabetics in the age group of $81-90 \mathrm{y}$, and an incidence of $100 \%$ was found among the non- diabetics in the same age group. An increase was noted in the prevalence of hearing loss as age progressed. However, studies by Mitchell et. al.(2009) ${ }^{[12]}$ and Horikawaet. al.(2013) ${ }^{[5]}$ showed that difference in hearing threshold remained consistent and not much significant changes were seen as age progressed.

In the present study, hearing loss was found to be typically bilateral, symmetrical, progressive and gradual in onset, asymmetry was also noted in some of the patients. Statistically significant differences in audiometric thresholds were found between case and control groups at 250,500, 1000 and $2000 \mathrm{~Hz}$ in both ears. Moreover the results became highly significant for both ears at 4000 and $8000 \mathrm{~Hz}$. [TABLE 5] These results are consistent with a study done with 5,140 individuals in $2008,{ }^{[13]}$ who found diabetic subjects had reduced hearing in all frequencies, and higher degrees of hypacusis at higher frequencies. In the study by Rajendranet. al., in $2011^{[9]}$ where the hearing loss started at $4000 \mathrm{~Hz}$ (mean 27.39 for right ear and mean 28.43 for left ear) in both the ears, it was maximum at $8000 \mathrm{~Hz}$ (mean 38.62 for right ear and 38.13 for left ear). Similar results were also seen in studies done by Krishnappaet. al. $(2014)^{[10]}$

36 males and 14 females were included in our study with a male female ratio of 2.5:1. Among the 36 males, 24 (66.67\%) patients was found to have sensorineural hearing loss and among the 14 females, 10 (71.42 $\%$.) patients had sensorineural hearing loss. Hence, in our study an increased prevalence of hearing loss was found among females [TABLE 2] in the diabetic group. Similarly, Irwin and Taylor (1978) ${ }^{[14]}$ observed females having higher affliction for hearing loss as compared to males. On the other hand, Rajendranet. al.(2011) andKrishnappa et. al.(2014) ${ }^{[10]}$ showed no gender difference in their studies. However, according to Shafeeqet. al. $(2015)^{[11]}$ male patients with diabetes had worse hearing than female patients with diabetes.

Further as duration progressed the prevelence of hearing loss also increased among the cases [TABLE $3]$ up to 10 years after which the duration of diabetes had no significant influence on hearing loss in our study. The study done by Celiket. al., in $1996^{[15]}$ observed that as the duration of diabetes increased to 15 years, the incidence of hearing loss also increased. However, after 15 years of diabetes, the influence on hearing loss was not significant. Similar results were seen in studies done by Krishnappaet. al. in $2014^{[10]}$;Shafeeq et. al., in $2015^{[11]}$ andMitchell et. al.,(2009) ${ }^{[12]}$ In 2011 Rajendranet. al., ${ }^{[9]}$ documented that the duration of diabetes (above or below 10 years) had no effect in the incidence of hearing loss in the diabetic group.

A positive relation between $\mathrm{HbAlc}$ level and severity of hearing loss was found. Patients with poor glycemic (HbA1c >8\%) control had higher prevalence of hearing loss (58.82\%) [TABLE 4] when compared with diabetics of moderately (14.71\%) and well controlled sugar levels (26.47\%). Similarly, Krishnappaet. al., in $2014^{[10]}$ documented that cases with poor glycemic (HbA1c >8\%) control had higher hearing loss $(89 \%)$ and 
also the severity of hearing loss seemed to increase with the poor glycemic status. Shafeeqet. al., in $2015^{[11]}$ also showed that diabetics with uncontrolled sugar levels $(\mathrm{HbA} 1 \mathrm{c}>8 \%)$ had increased prevalence of sensorineural hearing loss $(76.6 \%)$ when compared with diabetics of moderately $(68.1 \%)$ and well controlled $(45.1 \%)$ sugar levels. However, 2011 study by Rajendranet. al., ${ }^{[9]}$ found no effect of glycemic control (HbA1C level above or below 8 ) on the incidence of hearing loss among the diabetic group.

In our study, BERA (brainstem evoked response audiometry) performed at 110dB SPL (65dB nhl) showed that the latency of wave I of both ears at were found to be equal in the diabetics and controls. This suggests that the eight nerve transmission till the level of cochlear nucleus was not altered in the diabetics. This result was found to be consistent with those of Gupta et. al.(2010) ${ }^{[1]}$ The latency of wave III was delayed by $0.33 \mathrm{~ms}$ in both ears in diabetic group as compared to control group and the wave $\mathrm{V}$ in right ear and left ear by $0.23 \mathrm{~ms}$ and $0.27 \mathrm{~ms}$ respectively in our study. This delay was found to be highly significant on statistical analysis. The delay in the latency of wave III and V in the diabetics indicate neuropathy at brainstem and midbrain level in the auditory pathway.Gupta et. al., in $2010^{[1]}$ reported in their study that the latency of wave III was delayed by $0.39 \mathrm{msec}$, $0.42 \mathrm{msec}$ and $0.42 \mathrm{msec}$ at 70,80 and $90 \mathrm{~dB}$ respectively in diabetic group as compared to control group and the latency of wave $\mathrm{V}$ was found to be delayed by $0.48 \mathrm{msec}, 0.47 \mathrm{msec}$ and $0.50 \mathrm{msec}$ at 70,80 and $90 \mathrm{~dB}$ respectively. These delays were found to be highly significant on statistical analysis done by them, which is similar to the findings found in our study.In our study, the interpeak latency of wave I-III, III-V, I-V of right ear was delayed by $0.25 \mathrm{~ms}, 0.13 \mathrm{~ms}$ and $0.35 \mathrm{~ms}$ respectively and in the left ear by $0.33 \mathrm{~ms}, 0.16 \mathrm{~ms}$, and $0.34 \mathrm{~ms}$ respectively in diabetic group as compared to control group. This delay was found to be highly significant on statistical analysis. This suggests delayed transmission of the auditory stimulus in the auditory pathway of diabetics at the level of brainstem and midbrain. Similar findings were seen in the study done by Gupta et. al. $(2010)^{[1]}$

Gupta et. al.(2010) ${ }^{[1]}$ also documented that diabetics with peripheral neuropathy $(\mathrm{n}=13)$ had more incidence of delayed BERA $(n=12)$ tracings and thus concluded that diabetic subjects could suffer not only from peripheral and autonomic neuropathy but also from central neuropathy.Fideleet al., ${ }^{[16]}$ in 1984 found the latencies of ABR waves were significantly impaired in diabetic subjects as compare with normal. Peripheral transmission time (Wave I) and central transmission time (Wave I-V) were also significantly delayed in diabetic subjects.Sharma et al., ${ }^{[17]}$ in 2000 did a study to evaluate the auditory brain stem evoked responses changes in patients of diabetes mellitus at $2 \mathrm{KHz}, 4 \mathrm{KHz}, \& 6 \mathrm{KHz}$, frequencies. The number of diabetic subjects with abnormal values (>Mean wave latency in control subject $+2 \mathrm{SD}$ ) of absolute latencies of wave I, III $\& \mathrm{~V}$ and interpeak latencies I-III, III-V \& I-V were $64 \%(16 / 25), 72 \%(18 / 25) 84 \%(21 / 25)$ at $2 \mathrm{KHz}, 4 \mathrm{KHz} \& 6 \mathrm{KHz}$ respectively, suggesting that if brainstem evoked response audiometry is conducted at higher frequency like 6 $\mathrm{KHz}$ in diabetic patients, the involvement of central neural axis can be detected earlier. They also found a direct correlation between peripheral neuropathy and abnormal brain stem evoked responses. $85.71 \%$ of their subjects with diabetic neuropathy had abnormal brain stem evoked responses while only $36.36 \%$ subjects without neuropathy had abnormal brain stem evoked responses.

However Ashok Vermaet. al., (1984) ${ }^{[18]}$ reported normal auditory brain stem evoked responses in patients of diabetes mellitus. In three patients with mean duration of illness more than 15 years, he reported delayed responses since neuropathy is attributed to microangiopathy which is a long termsequelae of diabetes mellitus.

\section{Conclusion}

Although, this is a small study on limited number of patients and for a one year period prevalence of hearing loss was found to be high in type 2 diabetic patients $(68 \%)$ with hearing loss noted at all frequencies, which were highly significant at higher frequencies $(4000 \mathrm{~Hz}$ and $8000 \mathrm{~Hz})$. Prevelence of SNHL increased with duration of diabetes and decrease in glycaemic control.Hence proper control of sugar levels is necessary to prevent early onset of hearing loss in diabetic patients. BERA performed at 110dB SPL (65dB nhl), suggests that the eight nerve transmission till the level of cochlear nucleus is not altered however there is neuropathy at the level of brainstem and midbrain in the auditory pathway in diabetics. It is recommended that BERA should invariably be carried out in diabetic patients to detect the involvement of central neuronal axis earlier. Studies should be conducted on younger age group to rule to the presbycusis.

\section{References}

[1]. Gupta R, Aslam M, Hasan S A, Siddiqi S S. Type -2 diabetes mellitus and auditory brainstem responses - A hospital based study. Indian J EndocrMetab 2010;14:9-11

[2]. K.Park.Preventive and Social Medicine.19th edition.Banarsidas Bhanot.328-30

[3]. Jewett D. L., Romano M.N. and Williston J.S. (1970): Human auditory evoked potentials: Possible brain stem components detected on scalp. Science 167: 1517-1518

[4]. Who.int/mediacenter/factsheets/fs312/en/Horikawa C, Kodama S, Tanaka S, Fujihara K, Hirasawa R, Yachi Y, et al. Diabetes and risk of hearing impairment in adults: A meta- analysis. J ClinEndocrinolMetab 2013;98:1- 8.

[5]. Maia CAS, Campos CAH. Diabetes Mellitus as etiological factor of hearing loss. Braz J Otorhinolaryngol. 2005;71(2):208-14. 
[6]. Fukushima H, Cureoglu S, Schachern PA, Paparella MM, Harada T, Oktay MF. Effects of type 2 diabetes mellitus on cochlear structure in humans. Arch Otolaryngol Head Neck Surg 2006;132:934- 8.

[7]. Friedman SA, Schulman RH, Weiss S. Hearing and diabetic neuropathy. Arch Intern Med. 1975 ;135(4):573-6

[8]. Rajendran S, Anandhalakshmi, Mythili B, Vishwanatha R. Evaluation of the Incidence of sensorineural hearing loss in patients with type 2 diabetes mellitus. Int J Biol Med Res 2011;2:982- 7.

[9]. Krishnappa S, Naseeruddin K. A clinical study of age related hearing loss among diabetes patients. Indian J Otol 2014;20:160-5

[10]. Shafeeq M, Mohammed N A, Somayaji G, Mubeena, Kallikkadan HH, Sensorineural hearing loss in Type 2 diabetes mellitus. IOSR Journal of Dental and Medical Sciences (IOSR-JDMS) Volume 14, Issue 11 Ver. II (Nov. 2015), PP 56-61

[11]. Mitchell P, Gopinath B, McMahon CM, Rochtchina E, Wang JJ, Boyages SC, et al. Relationship of Type 2 diabetes to the prevalence, incidence and progression of age- related hearing loss. Diabet Med 2009;26:483- 8 .

[12]. Bainbridge KE, Hoffman HJ, Cowie CC. Diabetes and hearing impairment in the United States: audiometric evidence from the National Health and Nutrition Examination Survey, 1999 to 2004. Ann Intern Med. 2008;149(1):1-10.

[13]. Taylor,I.G.,Irwin,J. Some audiological aspects of diabetes mellitus. J Laryngol Otol.1978;92:99-113.

[14]. Celik O, Yalçin S, Celebi H, Oztürk A. Hearing loss in insulin dependent diabetes mellitus. AurisNasus Larynx.1996;23:127-32.

[15]. Fidele D, Martin A, Cardone C et al. Impaired auditory Brain Stem Evoked response in diabetes mellitus. Diabetes 1984;33:18051089.

[16]. Sharma R, Gupta SC, Tyagi I et al. Brain Stem Evoked Responses in patients with Diabetes Mellitus. Indian J of Otolaryngology and Head and Neck Surgery 2000;52(3); 221-229.

[17]. Ashok Verma, M. S. Bisht, G. K. Ahuja (1984) : Involvement of C. N. S. in diabetes mellitus. Journal of Neurology, Neurosurgery \& Psychiatry $47: 414-416$. 